\title{
Characterization of Calreticulin Expression in Mouse Endometrium during Embryo Implantation
}

\author{
SHU-QUN CHENG, JUN-LIN HE, YAN-LING DONG, XUE-QING LIU, YU-BIN DING, \\ RU-FEI GAO, YI TAN, QIAN YE, ZHEN-LING TIAN and YING-XIONG WANG
}

Laboratory of Reproductive Biology, Chongqing Medical University, No.1 Yixueyuan Road, Yuzhong District, Chongqing 400016, People's Republic of China

\begin{abstract}
Calreticulin (CRT), a $\mathrm{Ca}^{2+}$-binding storage protein and chaperone in the endoplasmic reticulum, modulates cell adhesiveness and integrin-dependent $\mathrm{Ca}^{2+}$ signaling. However, the role of CRT during implantation remains poorly understood. In the present study, we characterized the expression of $C R T$ mRNA and the protein in mouse endometria from pregnancy D1 to D7. Real-Time PCR and in situ hybridization results showed that the levels of $C R T$ mRNA in the endometria of pregnant mice were significantly higher than those of non-pregnant mice $(P<0.05)$, and increased gradually from pregnancy D1 to D4, reaching the maximum level on D4, followed by a plateau from D4 to D7. Using immunofluorescence histochemistry and western blot, changes of CRT expression in the endometria of pregnant mice were consistent with the expression of $C R T$ mRNA. Furthermore, antisense CRT oligodeoxynucleotide was injected into the uterus horns of pregnant mice (D3) to investigate its effect on embryo implantation. The result showed that the number of implanted embryos markedly decreased in the side of uterine horns receiving antisense CRT oligodeoxynucleotide $(P<0.05)$. These findings suggest that CRT may play an important role in embryo implantation in mice.
\end{abstract}

Key terms: Calreticulin; Endometrium; Embryo implantation; Mouse.

\section{INTRODUCTION}

Signals and molecular pathways responsible for endometrial development and receptivity to embryonic implantation are important issues in reproductive biomedicine because of their implication for treatment of infertility and assisted fertilization and implantation (Wang and Dey, 2006). Successful implantation depends on synchronization between the complex molecular and cellular events associated with development and differentiation of the blastocyst, and the receptivity of the endometrium. These events are finely regulated by a series of signals and molecules, including ovarian steroids and cytokines (Krüssel et al, 2003). Calreticulin(CRT) is an ancient and highly conserved $\mathrm{Ca}^{2+}$-binding chaperone with more than $90 \%$ amino acid homology in mammals (including human, rabbit, rat and mouse), which is expressed in various cells and tissues (Bedard et al, 2005). Previous studies have indicated that expression of CRT is associated with increased $\mathrm{Ca}^{2+}$ storage capacity of the endoplasmic reticulum (ER), $\mathrm{Ca}^{2+}$-binding chaperones in the lumen of the ER affect luminal $\mathrm{Ca}^{2+}$ concentrations $\left[\mathrm{Ca}^{2+} \mathrm{ER}\right]$ (Mesaeli et al, 1999; Meldolesi et al, 1998) and that agonist-induced changes in $\left[\mathrm{Ca}^{2+} \mathrm{ER}\right]$ affect ER function (Corbett et al, 2000). Coppolino and Papp et al reported that CRT is involved in cell adhesion via the induction of vinculin and $\mathrm{N}$-cadherin expression (Coppolino et al, 1995; Papp et al, 1999). It also affects cell adhesion

Corresponding authors: Prof. Ying-Xiong WANG and Jun-Lin HE, Laboratory of Reproductive Biology, Chongqing Medical University, No.1 Yixueyuan Road, Yuzhong District, Chongqing 400016, People's Republic of China. Phone: 86-23-68485926; Fax: 86-23-68485008; Email: wyx61221@yahoo.com.cn. hejunlin_11@yahoo.com.cn 
because transient down-regulation of CRT reduces attachment of cells to extracellular matrix substrata (Otteken et al, 1996). In addition, CRT modulates integrindependent $\mathrm{Ca}^{2+}$ signaling and steroidsensitive gene expression (Michalak et al, 1999). During the initial stages of embryo implantation, integrins have central roles in the regulation of adhesion and migratory events at the embryo-maternal interface (Burrows et al, 1996). Integrins are capable of influencing and mediating adhesion, migration, invasion, cytoskeleton reorganization and cellular signaling, which are all critical for embryo implantation, via binding to various extracellular matrix (ECM) components and cell adhesion molecules (Burghardt et al, 2002). These findings suggest that CRT may play an important role in the process of embryo implantation. However, the expression and the role of CRT in the uterus during early pregnancy remain unknown. This study aims to examine the expression characteristics of CRT in the mouse endometrium during early pregnancy and the effect of CRT on embryo implantation in order to probe the role of CRT in implantation.

\section{MATERIALS AND METHODS}

\section{Animals and endometria isolation}

Female and male NIH mice (6-to-8-wk-old) were obtained from the Laboratory Animal Center of Chongqing Medical University [Chongqing, China (Certificate: SCXK (YU) 2006002]). All mice were housed in specific pathogen free (SPF) rooms with a controlled light schedule (12L: 12D) and controlled temperature range $\left(22-25^{\circ} \mathrm{C}\right)$ with free access to food and water. All animal procedures were approved by the Ethics Committee, State Key Laboratory of Reproductive Biology, Institute of Zoology, Chinese Academy of Sciences. The estrus females, whose estrous cycles were identified by analysis of exfoliated vaginal cells under a microscope, were bred with fertile males (female to male: 2 to 1 ) overnight (12h) and the vaginal plugs were checked the following morning. The day of vaginal plug was considered as Day 1of pregnancy (D1). Pregnant mice were divided into seven groups (D1, D2, D3, D4, D5, D6, and D7) with 20 mice in each group, 20 non-pregnant estrus mice were chosen as controls (D0). Twenty supernumerary D3 mice were used for CRT function study.

Mice in each group were killed between 0800-0900 h by cervical dislocation after intraperitoneal injection of $1 \%$ butaylone. Uterine horns were immediately dissected and flushed with saline, and then endometrial tissues were squeezed out from uterine horns by use of fine forceps under an anatomical microscope according to the procedures described by Tan Y (Tan Y et al, 2001). The isolated endometrial tissues of 10 mice in each group were immediately stored in liquid nitrogen for Real-Time PCR and western blot. The tissues of the other 10 mice in each group were fixed in $4 \%$ paraformaldehyde, embedded in paraffin for immunofluorescence histochemistry and in situ hybridization. In addition, another 20 D3 mice received uterine horns injection of CRT antisense oligonucleotide for CRT function study.

Real-Time PCR of CRT mRNA in mice endometria

\section{RNA extraction}

Total RNA of mouse endometria was extracted using the total RNA isolation reagent (TRI reagent, Promage, Madison, WI, USA) according to the manufacturer's instructions. Quantification and purity of the total RNA was examined using UV spectrophotometer, $A 260 / A 280 \geq 1.8$ was the standard. Integrity of the total RNA was identified by agarose gel electrophoresis.

\section{Real-Time PCR}

The reverse transcription of cDNA was done in a $25 \mu 1$ reaction system, containing $1 \mu \mathrm{l}$ RNA $(1 \mu \mathrm{g} / \mu \mathrm{l}), 500 \mathrm{ng}$ Oligo-dT, $5 \times$ buffer $5 \mu \mathrm{l}, M-M L V(200 \mathrm{U} / \mu \mathrm{l}) 1 \mu \mathrm{l}$, RNAi (25 U)0.5 $\mu \mathrm{l}$, dNTPs $(10 \mathrm{mmol} / \mathrm{L}) 5 \mu \mathrm{l}$, added DEPC- $\mathrm{H}_{2} \mathrm{O}$ to $25 \mu \mathrm{l}$. The reaction 
conditions were for $5 \mathrm{~min}$ at $70{ }^{\circ} \mathrm{C}, 60 \mathrm{~min}$ at $42^{\circ} \mathrm{C}$ and $10 \mathrm{~min}$ at $70{ }^{\circ} \mathrm{C}$. The primers for $C R T$ and $\beta$-actin were designed using the primer design program (Primer Premier $5)$ and synthesized by Dingguo BioTechnologies Co, Ltd., as shown in table 1. Quantification of the transcripts was carried out in the iQ5 Real-Time PCR Detection System (Bio-Rad, Hercules, CA). Templates for PCR were obtained by reverse transcription of cDNA. Real-Time PCR was performed in a total $25 \mu \mathrm{l}$ reaction system (the SYBR Green I PCR Reagent kit, TaKaRa, Dalian). The reaction conditions were for $3 \mathrm{~min}$ at $94^{\circ} \mathrm{C}, 5 \mathrm{~s}$ at $94^{\circ} \mathrm{C}$ and $30 \mathrm{~s}$ at $54^{\circ} \mathrm{C}$, for 40 cycles. The fluorescence signal of 3rd to 15 th cycles was settled as a fluorescent background signal and the baseline was adjusted accordingly. Relative quantification of the expression level of $C R T$ and $\beta$-actin mRNA were calculated by the following method: for each reaction to amplify $C R T$ target gene and $\beta$-actin gene, the $C_{t}$ value was determined. The ratio of each $C R T$ target mRNA to $\beta$-actin mRNA was calculated by the formula $2^{-\Delta \Delta C t}$. The gene expression rate was obtained by normalizing the amount of $C R T$ mRNA with that of $\beta$-actin mRNA.

\section{In situ hybridization}

Digoxigenin-labeled sense and probes of were designed and synthesized by Dingguo BioTechnologies Co, Ltd. The sequence of antisense CRT probe is: 5' -tgggactttctgccac ccaagaagataaaggaccctgatgctgccaagcc-3'. In situ hybridization was carried out according to the manufacturer's instructions. The mouse endometria samples were fixed immediately in $4 \%$ paraformaldehyde and embedded in paraffin. Sections $(7 \mu \mathrm{m})$ were cut, de-paraffinized and rehydrated. The sections were digested with $0.1 \mathrm{mg} / \mathrm{ml}$ proteinase $\mathrm{K}$ for $7 \mathrm{~min}$ at $37^{\circ} \mathrm{C}$, and washed three times with PBS. The next step consisted of the prehybridization in hybridization buffer for $3 \mathrm{hr}$ at $42^{\circ} \mathrm{C}$ and hybridization at $42^{\circ} \mathrm{C}$ overnight in hybridization buffer containing digoxigenin-labeled sense and antisense probe of CRT at a final concentration of 20ng/ul. After hybridization, the sections were washed for $10 \mathrm{~min}$ with $2 \times \mathrm{SSC}$, $0.5 \times \mathrm{SSC}$ for $15 \mathrm{~min}$ and $0.2 \times \mathrm{SSC}$ for $15 \mathrm{~min}$ at $37^{\circ} \mathrm{C}$ and incubated in $5 \%(\mathrm{w} / \mathrm{v})$ bovine serum albumin for $30 \mathrm{~min}$ at room temperature, then incubated respectively in anti-rabbit CRT antibody labeled with digoxigen (1: 100) and goat anti-rabbit IgG conjugated to alkaline phosphatase (1: 100) for $60 \mathrm{~min}$ at $37^{\circ} \mathrm{C}$, washed in PBS for 5 min. The signal was visualized with 5bromo-4-chloro-3-indolyl phosphate and nitroblue tetrazolium. The signal intensity of CRT mRNA expression was quantified using Chengdu Jinpan Media Mix Image Analysis Software 1.0 version (Chengdu, China).

\section{Immunofluorescence histochemistry}

The mouse endometria samples were fixed immediately in $4 \%$ paraformaldehyde and embedded in paraffin. Sections $(8 \mu \mathrm{m})$ were cut, deparaffinized and rehydrated. The sections were soaked in $3 \% \mathrm{H}_{2} \mathrm{O}_{2}$ solution for $15 \mathrm{~min}$ at room temperature to eliminate endogenous peroxidase activity. The sections were placed in $0.01 \mathrm{M}$ citrate buffer $\left(\mathrm{pH} \mathrm{7.0)}\right.$ for $15 \mathrm{~min}$ at $95^{\circ} \mathrm{C}$ for antigen retrieval, and then rinsed at least three

TABLE 1

Sequences of primers for real-time PCR

\begin{tabular}{llc}
\hline Gene & Primer sequence & Product size \\
\hline Calreticulin & F: 5'-TACGCACTGTCCGCCAAAT-3' & $132 \mathrm{bp}$ \\
& R: 5'-GTCCAAACCACTCGGAAACAG-3' & \\
$\beta$-actin & F: 5'-CCTGAGGCTCTTTTCCAGCC-3' & $110 \mathrm{bp}$ \\
& R: 5'-TAGAGGTCTTTACGGATGTCAACGT-3' & \\
\hline
\end{tabular}


times with PBS. The sections were incubated with monoclonal anti-rabbit CRT antibody (1: 30 dilution with PBS) (from Santa Cruz Biotechnology Inc) for $2 \mathrm{~h}$ at $37^{\circ} \mathrm{C}$, washed for $10 \mathrm{~min}$ with $\mathrm{PBS}$. The sections were incubated with a secondary antibody of goat anti-rabbit IgG labeled with fluorescein isothiocyanate (FITC) for $2 \mathrm{~h}$ at $37^{\circ} \mathrm{C}$ (Santa Cruz, CA, USA), following extensive washing with PBS. As a negative control, CRT primary antibody was replaced with PBS. The localization of CRT protein expression was analyzed under a confocal laser scanning microscope (LEICA TCS SP2, Germany) and the levels of CRT expression were quantified with Chengdu Jinpan Media Mix Image Analysis Software 1.0 version (Chengdu, China).

\section{Western blot analysis}

Total protein was extracted from the mouse endometria of each group using the total protein Tripure reagent kit (Dalian TaKaRa, China) according to the manufacturer's instructions. Protein concentration was measured by the Bradford assay. Protein samples $(30 \mu \mathrm{g}$ each sample) were subjected to $10 \%$ SDS-polyacrylamide gel electrophoresis and then transferred onto polyvinylidene difluoride membrane using a Bio-Rad electroblot apparatus (Bio-Rad, Beijing, China). The membrane was incubated in blocking PBS containing $0.05 \%$ Tween-20(TBST) and 5\% nonfat milk for 1 $\mathrm{h}$ at room temperature. Immunoblot analyses were accomplished by incubating the membranes with monoclonal rabbit antiCRT antibody (1: 2000 dilution in 5\% milkTBST) (Santa Cruz, CA, USA) overnight at $4^{\circ} \mathrm{C}$, followed by incubating with secondary antibody (goat anti-rabbit $\mathrm{IgG}$ ) conjugated with horseradish peroxidase (Zhongshan Biosciences Inc, Beijing, China) for $2 \mathrm{~h}$ at $37^{\circ} \mathrm{C}$. After a final washing in TBST for $1 \mathrm{~h}$, protein bands were visualized by diaminobenzidine tetrahydrochloride (DAB). Densitometry analysis of CRT expression was performed using Quantity One version 4.4.0 analysis software. Primary rabbit antiCRT antibody was replaced with rabbit antiactin antibody (Zhongshan Biotechnology) as an internal control.
CRT function study during early embryo implantation

To further determine whether the CRT may play a role in embryo implantation, the female mice of pregnancy D3 were given a uterine horn injection of antisense CRT oligodeoxynucleotide according to the procedures described by Zhu (Zhu LJ, et al. 1998). The oligodeoxynucleotides were designed and synthesized (Dalian TaKaRa, China) according to the sequence of mouse CRT gene cDNA. The sequences of oligodeoxynucleotides were: sense CRT oligodeoxynucleotide: 5'-CGGCCCGCCA TGCTCCTTTCG-3'; antisense CRT oligodeoxynucleotide: 5'-CGAAAGGAGC ATGGCGGGCCG-3'. The antisense CRT oligodeoxynucleotide was complementary to bases $125-145 \mathrm{bp}$ within exon I of the mouse CRT (GenBank Accession Number: NM_007591.3). Analysis of homology between the synthesized oligomer and the rodent sequences present in GenBank data bases by Genetics Computer Group sequence analysis software package revealed that the synthesized oligomer was specifically complementary only to CRT mRNA.

Antisense CRT oligodeoxynucleotide of $81 \mathrm{ug}$ was dissolved in 50ul $0.9 \% \mathrm{NaCl}$ solution for stock solution (solution A). Lipofectamine2000 6ul was diluted with 50 ul $0.9 \% \mathrm{NaCl}$ solution (solution B). A working solution was prepared by mixture of the two solutions before injection. After female mice were anesthetized, disinfected and underwent midventral laparotomy on D3 of pregnancy between 0800-0900 h, the right uterine horn of each mouse $(n=10)$ was fixed with forceps, and the needle was very slowly introduced as close as possible to the cervix in the uterine horn. The working solution $(8 \mu 1)$ containing antisense CRT oligodeoxynucleotide was injected into the right uterine horn of each animal. Each animal served as her own control, with the left uterine horn receiving the same volume of sense CRT oligodeoxynucleotide solution. In addition, the two sides of uterine of each mouse $(n=10)$ on pregnancy D3 were only injected with $8 \mu \mathrm{l}$ of $0.9 \% \mathrm{NaCl}$ solution as a loading control. On D8 of pregnancy, all animal were killed between 8: 00AM-9: 
00AM by cervical dislocation after intraperitoneal injection of $1 \%$ butaylone, and then the uterine were removed by laparotomy and the number of implanted embryos was recorded in each uterine horn.

\section{Statistical analysis}

All statistical data obtained from the experiment were analyzed using the Statistical Package for the Social Sciences software (SPSS for Windows package release 10.0, SPSS Inc., Chicago, IL, USA). Statistical significance was determined using one-way ANOVA. Post-Hoc comparisons between groups were made by Fisher's protected least-significance-difference test. Values were means \pm S.D. Differences were considered significant at $P<0.05$.

\section{RESULTS}

CRT mRNA expression in mouse endometria during early pregnancy

The level of CRT mRNA was detected in endometria of pregnant and non-pregnant mice by Real-Time PCR. The result showed that the relative ratio of $C R T$ mRNA on D1,
D2, D3, D4, D5, D6, D7 was 1.45 \pm 0.013 , $1.53 \pm 0.015,1.65 \pm 0.011,1.98 \pm 0.009$, $1.97 \pm 0.010,1.88 \pm 0.012$ and $1.87 \pm 0.010$, respectively (relative ratio of $C R T$ mRNA on D0 was set 1 as a reference, Fig.1). The level of $C R T$ mRNA of pregnant mice showed a gradual increasing trend as days passed, reaching the maximum level on D4, followed by a plateau in CRT mRNA expression. Analysis of variance showed that the expression of $C R T$ mRNA has significant differences between pregnant and non-pregnant mice $(P<0.05)$. In situ hybridization of the endometria sections further confirmed the results obtained by Real-Time PCR. CRT mRNA was mainly expressed in the luminal epithelium, glandular epithelium and stroma cells during this period (Fig. 2). No signal was detected when the antisense probe was replaced with the sense probe (Fig. 2NC). The weak signal of $C R T$ mRNA was present in the endometrial gland epithelium and stroma cells of non-pregnant mice (Fig.2).

\section{Expression of CRT protein in the endometrium}

The quantitative change of CRT expression in endometria was estimated by

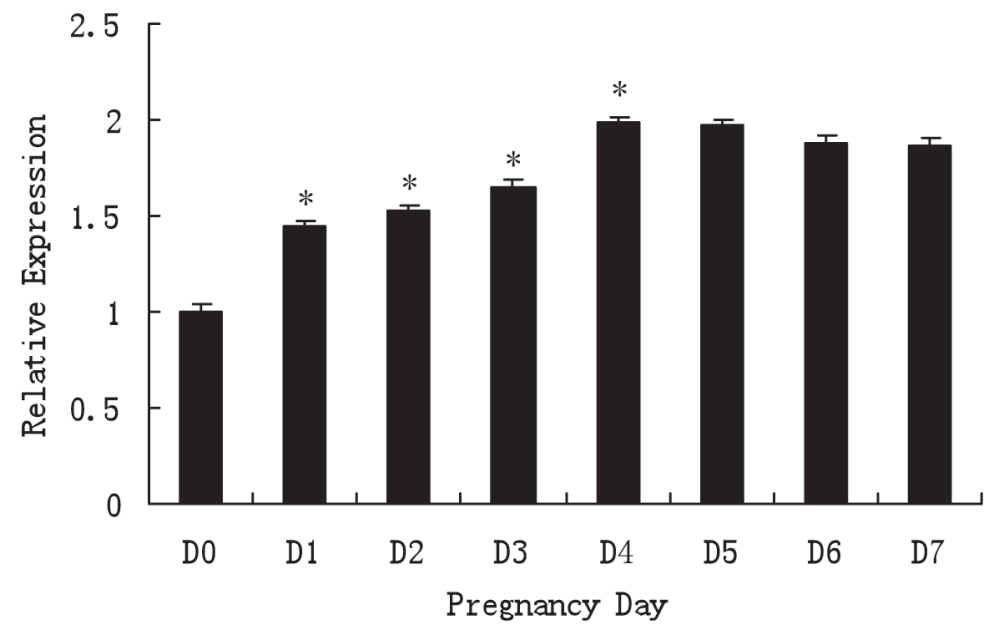

Figure 1: Real-Time PCR analysis of CRT mRNA expression in mouse endometria Real-Time PCR analyses of CRT mRNA expression from D0 to D7. Gene expression values from pregnancy endimetria were expressed relative to D0 values and represent the means \pm SD from 20 separate mouse endometria of each group, respectively. Levels of $\beta$-actin mRNA were used as an internal control. D0 means non-pregnancy; D1 to D7 mean day 3, day 4, day 5, day 6, day 7 of pregnancy, respectively. D1, D2, D3 and D4 versus D0, respectively $(* P<0.05)$. 
(A)
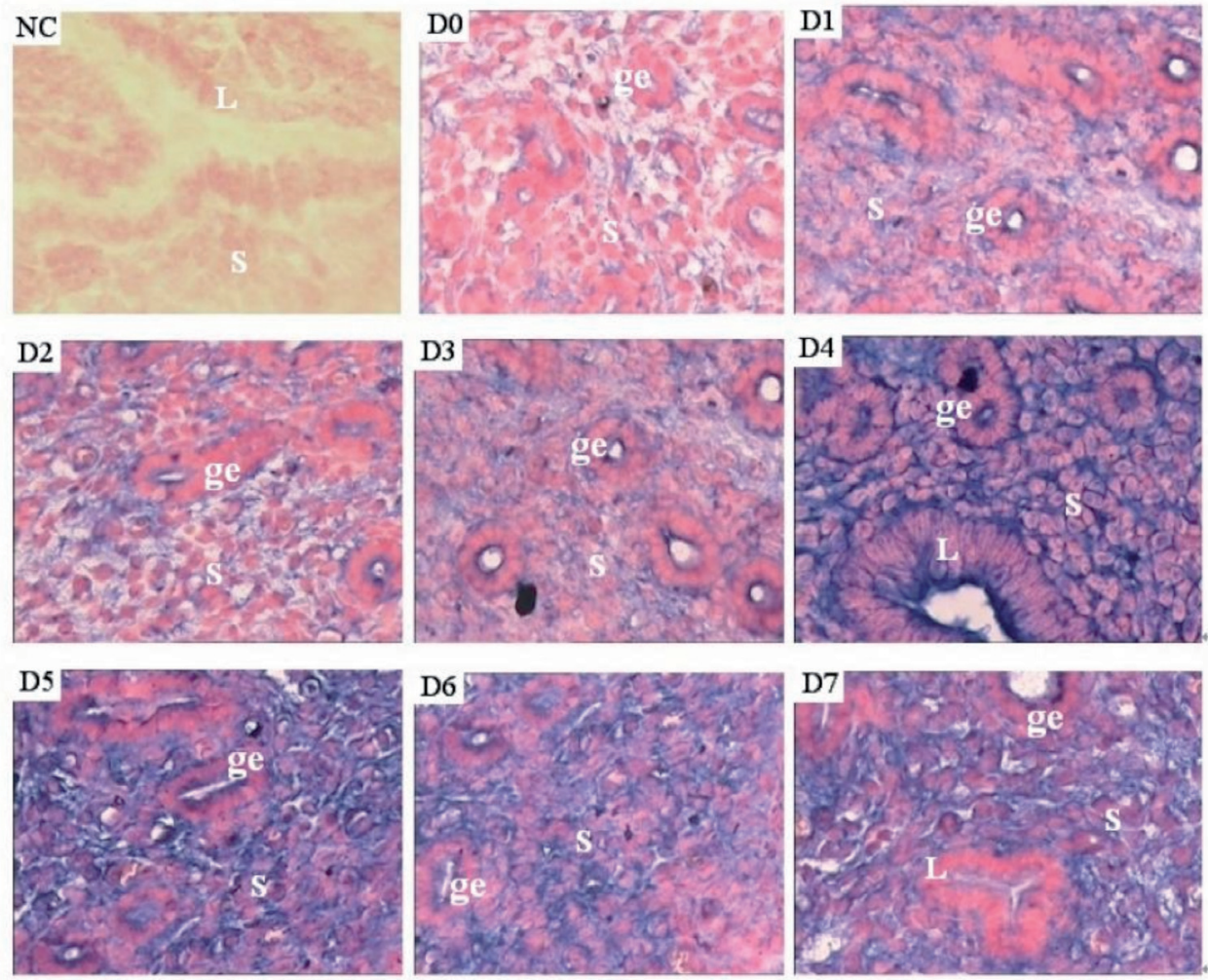

(B)

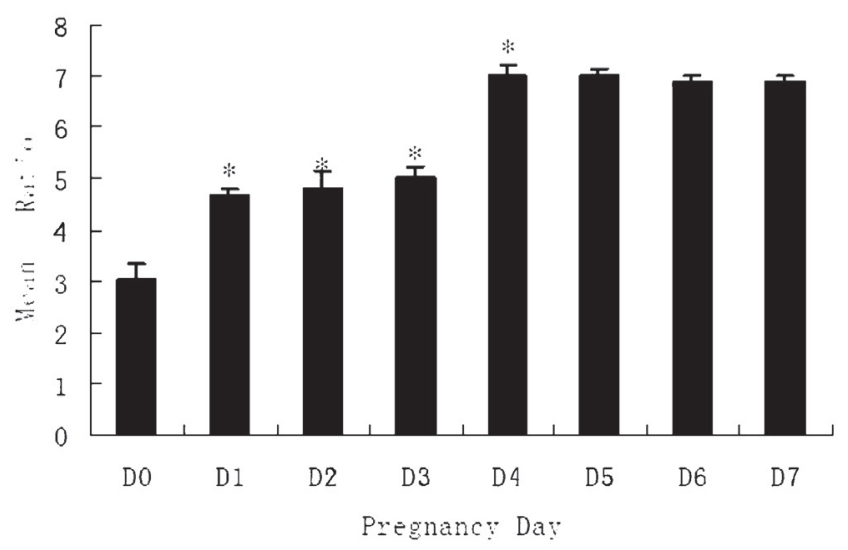

Figure 2: In situ hybridization for CRT mRNA expression in mouse endometria The location and the level of $C R T$ mRNA were examined by in situ hybrididization using DIG-labeled oligonucleotide probe. Blue staining was determined as positive. (A): NC represented negative control; D0 means non-pregnancy; D1, D2, D3, D4, D5, D6 and D7 represented Day 1, Day 2, Day 3, Day 4, Day 5, Day 6 and Day 7 of pregnancy, respectively. The level of $C R T$ mRNA increased gradually from D1 to D7, reached a maximum level on D4, followed by a plateau was maintained from $\mathrm{D} 4$ to $\mathrm{D} 7$. $\mathrm{L}=$ luminal epithelium; $\mathrm{S}=$ stromal cell; $\mathrm{G}=$ glandular epithelium. (B): The signal intensity of $C R T$ mRNA was quantified using Chengdu Jinpan Media Mix Image Analysis Software 1.0 version (Chengdu, China). D1, D2, D3 and D4 versus D0, respectively $(* P<0.05)$. 
Western blot, as shown in Fig. 3. The protein level was gradually increased from D1 to D7 in a time-dependent manner, reached the maximal level on D4 (Fig. 3), just the time of implantation window. Densitometric analysis indicated that the intensity of CRT expression was higher in pregnant mice than in non-pregnant mice $(P<0.05)$.

Immunofluorescence histochemistry analysis showed that The CRT protein was mainly located in the uterine luminal, glandular epithelium and stromal cells. The highest expression was also observed on D4 (Fig. 4). The levels and change of CRT protein expression also coincided with the mRNA levels detected by Real-Time PCR.

Functional study of CRT during embryo implantation

The effect of blockage of CRT gene expression on embryonic implantation was investigated using an antisense CRT oligodeoxynucleotide as a blocker on D3. The results indicated that the number of implanted embryos in the right uterine horns receiving antisense CRT

(A)

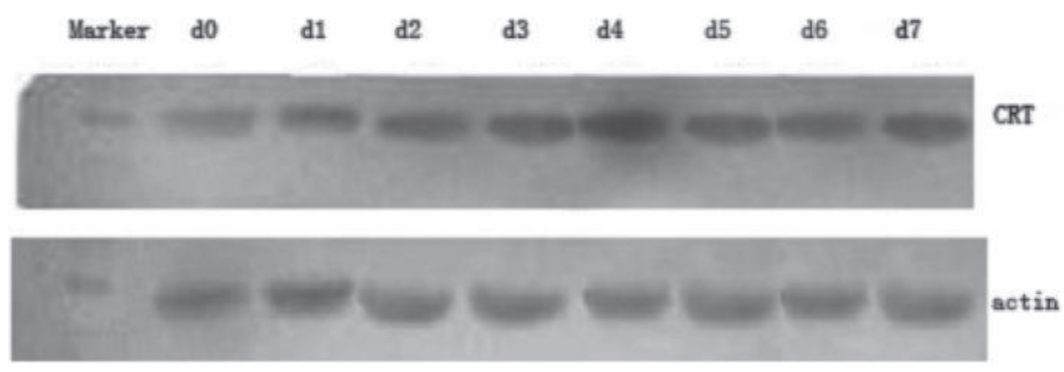

(B)

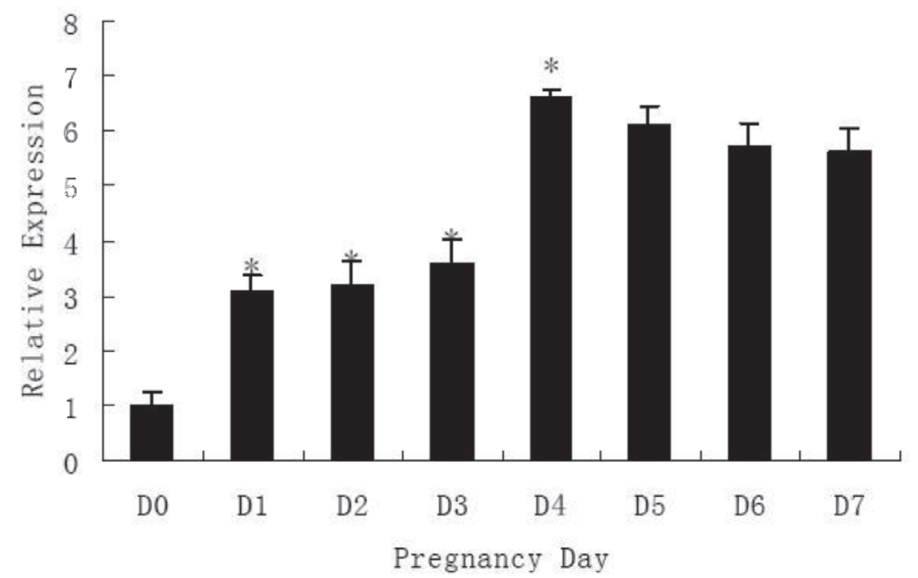

Figure 3. Western blot for CRT protein expression in mouse endometria The levels of CRT expression during early pregnancy were determined by western blotting using anti-CRT antibody (from Santa Cruz Biotechnology Inc). (A): d0: non-pregnancy; d1, d2, d3, d4, d5, d6 and d7 represented Day 1, Day 2, Day 3, Day 4, Day 5, Day 6 and Day 7 of pregnancy, respectively; Levels of $\beta$-actin were used as internal control. (B): Densitometry analysis of CRT expression was performed using Quantity One version 4.4.0 analysis software. The level of CRT expression increased gradually from D1 to D7, reaching a maximum level on D4, followed by a plateau that was maintained from D4 to D7, D1, D2, D3 and D4 versus D0, respectively $(* P<0.05)$ 
(A)

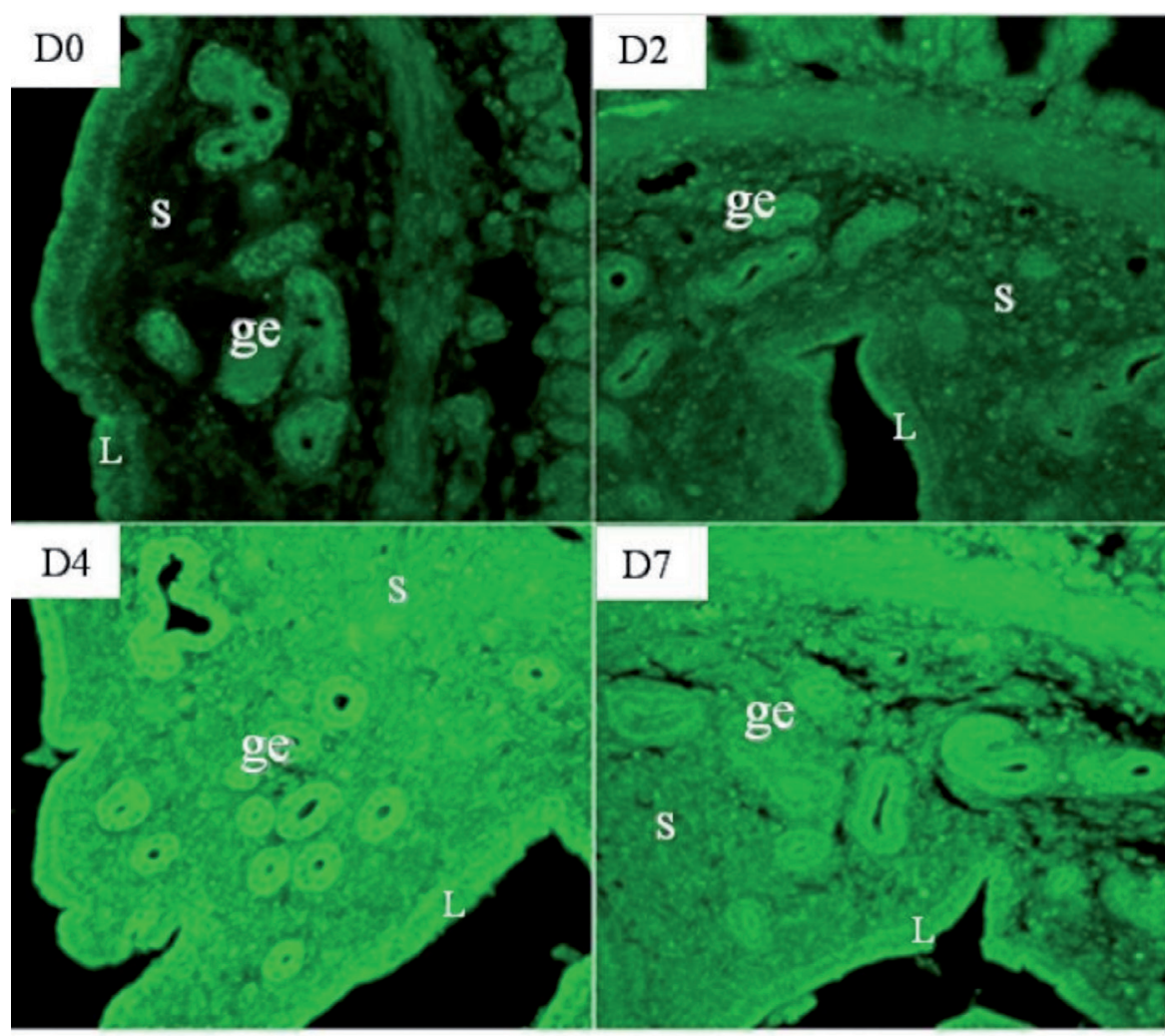

(B)

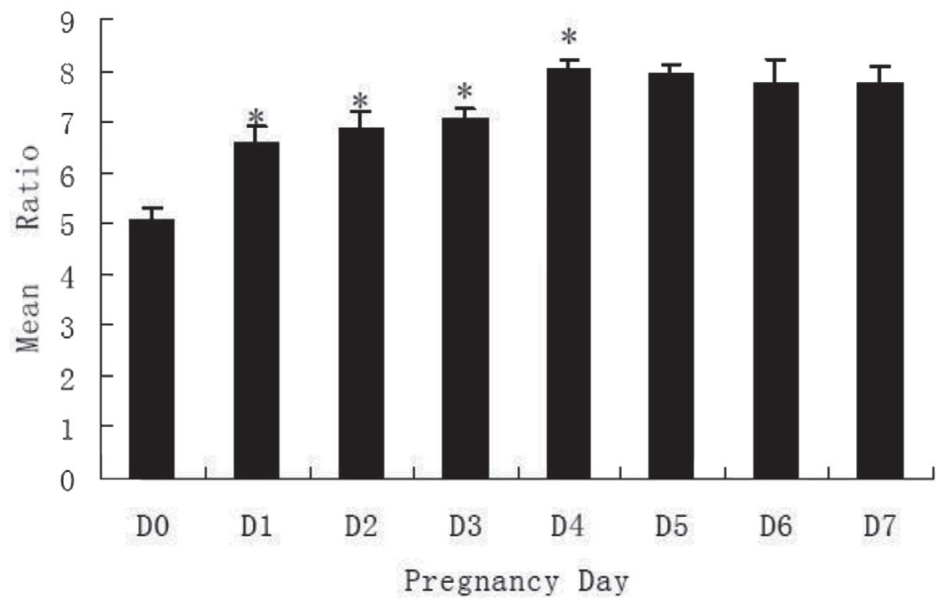

Figure 4. Imunofluorescence histochemistry for CRT protein expression in mouse endometria The location and the level of CRT protein in endometria during early pregnancy were determined by Imunofluorescence histochemistry using anti-rabbit CRT antibody (Santa Cruz Biotechnology Inc). Green staining was determined as positive. (A): D0: non-pregnancy; D2, D4 and D7 represented Day 2, Day4 and Day7 of pregnancy, respectively; $\mathrm{L}=$ luminal epithelium; $\mathrm{S}=$ stromal cell; $\mathrm{G}=$ glandular epithelium. (B): The fluorescence intensity of CRT protein expression was quantified using Chengdu Jinpan Media Mix Image Analysis Software 1.0 version (Chengdu, China). D1, D2, D3 and D4 versus D0, respectively $(* P<0.05)$ 


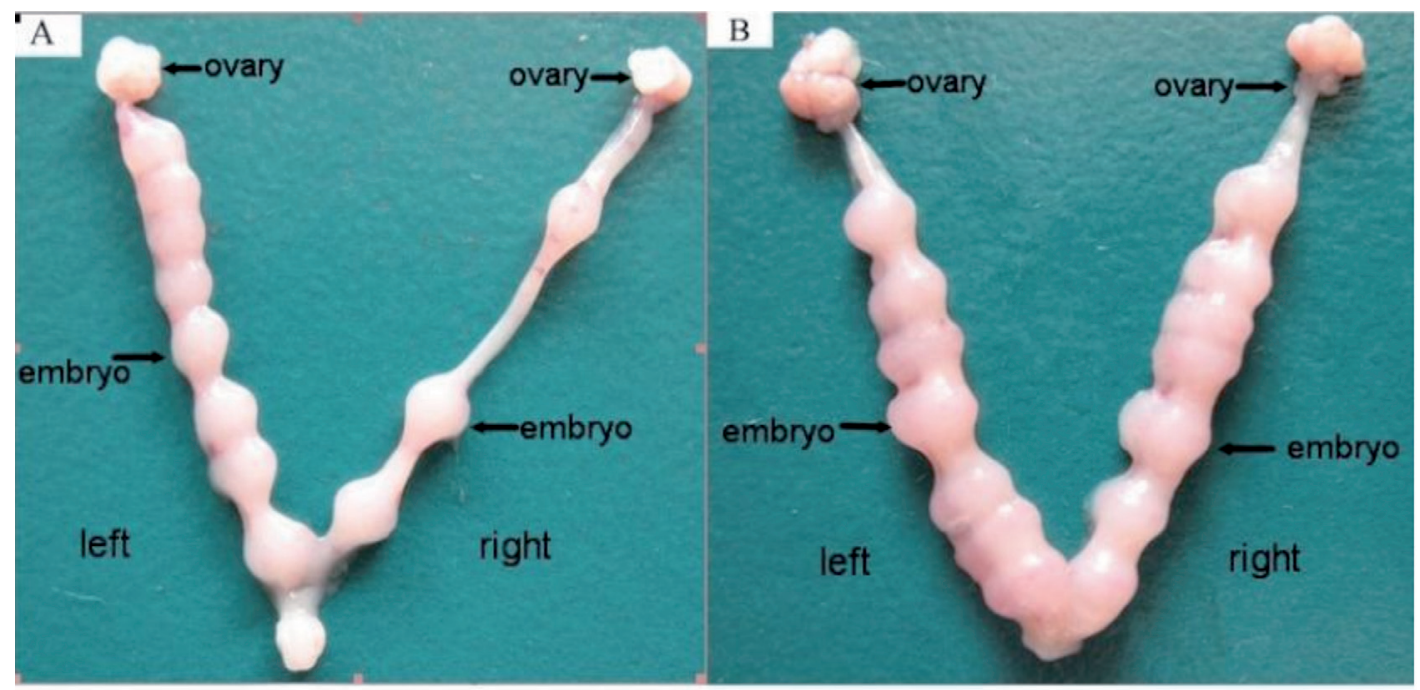

C

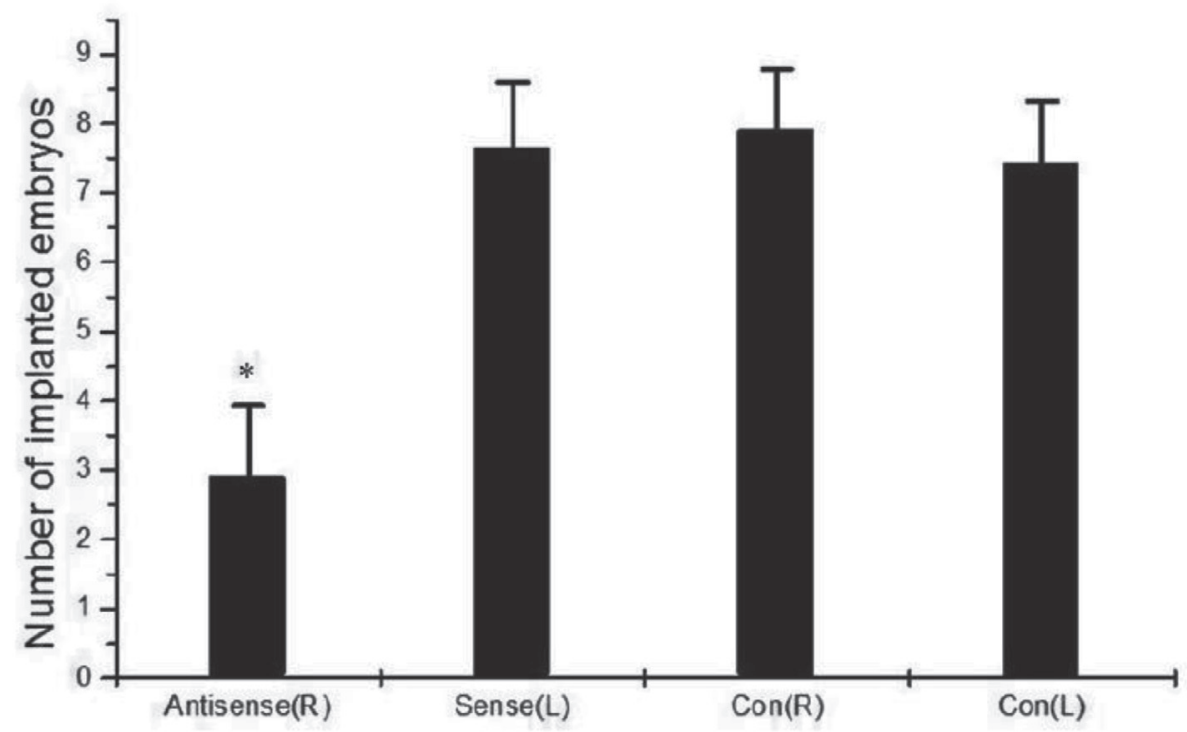

Figure 5. Effect of antisense CRT oligodeoxynucleotide on number of implanted embryos:

The function of CRT was blocked by uterine horn injection of antisense CRT oligodeoxynucleotide at $0800-0900 \mathrm{~h}$ on D3, and then the number of implanted embryos was recorded on D8 by dissection. (A): Representative uterine horns from one mouse of the treatment group $(n=10)$, the right horn: receiving antisense CRT oligodeoxynucleotide; the left horn: receiving sense CRT oligodeoxynucleotide. The number of implanted embryos in the right uterus was markedly lower than that of the left $(* P<0.05)$. (B): Representative uterine horns from one mouse of the loading control group $(\mathrm{n}=10)$ by injecting $0.9 \% \mathrm{NaCl}$ solution on both sides of the uterus. The saline did not affect implantation $(P>0.05)$. $(\mathrm{C})$ : The mean number $( \pm \mathrm{SD})$ of implanted embryos in the uterine horns of the treatment- and control groups. Unilateral antisense CRT oligodeoxynucleotide administration significantly reduced implantations in the injected horn $(* P<0.05)$. The numbers of implanted embryos in the uterine horns receiving sense CRT oligodeoxynucleotide and saline solution treatment were not significantly different $(P>0.05)$. 
oligodeoxynucleotide was significantly lower than in the left uterine horns receiving sense CRT oligodeoxynucleotide (the right: $2.92 \pm 1.02$; the left: $7.66 \pm 0.93$; $P<0.05$; Fig. 5A). In addition, the number of implanted embryos in uterine horns of the right and the left receiving $0.9 \% \mathrm{NaCl}$ solution did not decrease $(7.93 \pm 0.86$ and $7.45 \pm 0.87$, respectively. $P>0.05$; Fig. 5B). These data showed that the total number of implanted embryos was affected by uterus horn injection with antisense CRT oligodeoxynucleotide ( $* P<0.05$; Fig. 5C).

\section{DISCUSSION}

Endometrial receptivity towards embryo implantation is a complex event that involves various processes, such as blastocyst adhesion, trophoblast invasion, decidualization and cell-to-cell interaction, controlled by a variety of molecules produced by endometrium, embryo and ovary (Liu YX, 2004). The dialog between the ovary and the endometrium provides the hormonal environment for establishment of a successful pregnancy. The hormones estrogen and progesterone act coordinately to stimulate the expression of key molecules necessary for embryos to attach to and invade. It is thought that initial attachment of the embryo involves cell adhesion events. The best characterized cell adhesion molecule on the luminal surface of the endometrium is the alpha-beta 3 integrin. CRT can interact with a-subunits of integrin receptors via the highly conserved KXGFFKR sequence in the cytoplasmic domain and is considered a potential integrin regulatory protein. This interaction is important in mediating cell attachment and spreading on extracellular matrix (EMC) substrates (Coppolino et al., 1999; Reilly et al, 2004). Integrins are a large family of transmembrane heterodimeric proteins that mediate cell-cell and cell-ECM adhesion by its interaction with the ECM including vitronectin, fibronection. Integrins are considered as markers of the implantation window and contribute to the transformation of endometrium from the non-adhesion to the adhesion status for embryo adhesion and implantation (Wang and Armant, 2002; Lessey and Arnold, 1998). These findings strongly imply that CRT may be involved in embryo implantation. Consequently, we examined the characteristics of CRT expression in the endometrium during early pregnancy. Our results demonstrated that levels of $C R T$ mRNA and its protein in the endometria of pregnant mice were significantly higher than those of nonpregnant mice, and increased gradually from $D 1$ to $D 7$, reaching the maximum level on D4 and D5 (just around implantation window), followed by maintaining high levels on D6 and D7. Expression of this molecule were mainly observed in the luminal, glandular epithelia and stromal cells and showed a temporal and spatial pattern of relationship with the establishment of early pregnancy, the highest level appeared on D4. The previous study indicated that the adhesive reaction of blastocyst trophectoderm with the luminal epithelium initiate the implantation. Early event of implantation occurs on the midnight of D4 or early morning of D5 in mice (Wang X, et al, 2004). The expression of integrins is necessary for the adhesion and invasive capability of blastocyst to endometrium during the implantation window (Lessey et al, 1992; Lessey et at, 1994) and changes in CRT expression in endometrium may regulate integrin function and cell adhesion to facilitate the implantation process (Leung-Hagestei et al, 1994; Fadel et al, 1994; 2001). Our results show that the highest level of CRT expression in endometrium is concordant with "the implantation window" (on D4 and D5) and a role for CRT interacting with integrins to regulate blatocyst adhesion and invasion into uterine endometrium. The observation strongly implied that CRT may be a critical factor during implantation. Given the increase of the CRT levels in the uterus, even when the embryos are still in the oviduct on pregnancy, we think that the embryo, as a stimulus, may induce a series of physiologic reactions of endometrium, including production of a variety of molecules benefitting from endometrial cell differentiation, blastcyst adhesion, 
trophblast invasion and decidualization. The event is very important for implantation priming and protection of implanted embryo when the embryo enters the uterus. Although the embryos are still in the oviduct on pregnancy D1, a series of molecules related to implantation, including CRT, begin to be expressed in endometrium in order to provide a suitable endometrial circumstance for the implantation.

The results of the present study indicate that a temporal-spatial pattern of CRT expression in endometria during the implantation process might be essential for implantation. The presence of the embryo in the uterus as a stimulus may be important for increasing CRT expression. One can expect that a reduction of CRT expression could prevent acquisition of a receptive state of the endometrium, leading to a failure of implantation. Therefore, we designed an experiment directly injecting antisense CRT oligodeoxynucleotide into pregnant mouse uterus on D3 in order to investigate the function of CRT during implantation. Previous study confirmed that it is effective for inhibition of gene expression through uterine horns injecting oligodeoxynucleotide (Zhu et al, 1998). Especially recently, Yuan et al certified further that oligodeoxynucleotide can be effectively taken up by the uterine luminal, glandular epithelium and stromal cells (Yuan JX et al, 2009). It is known that antisense oligodeoxynucleotide has a halflife of 24-28 hours in certain tissues (Wagner RW, 1994). Therefore, one may expect that the antisense CRT oligodeoxynucleotide by uterine horns injection on D3 is effective for suppresion of CRT expression in the subsequent Day 4-Day 5 of pregnancy (implantation window). In this study, the number of implanted embryos was significantly lower in the uterus horn injection of antisense CRT oligodeoxynucleotide on D3. The statistical analysis of the difference in the number of implanted embryos between the antisense- and sense oligodeoxynucleotidetreated groups showed that embryo implantation was indeed inhibited with the treatment of CRT antisense oligodeoxynucleotide $\quad(P<0.05)$. Our findings strongly imply that CRT may be involved in the initial stages of embryo implantation. However, it can not be ruled out that the CRT antisense oligonucleotide may have direct inhibitory effects on the adhesive character of integrins.

In summary, our data have demonstrated a significant increase of CRT expression on D4 and D5. It seems that CRT plays an important role in the implantation process in rodents and this may be similar in humans. However, further studies are necessary to reveal the molecular mechanisms of CRT involvement in this process.

\section{ACKNOWLEDGEMENTS}

We are grateful to Prof. Thomas G for critically reading the manuscript and the members of our laboratory for many helpful discussions. This study was supported by National Natural Science Foundation (No.30270510, 30700898) and Natural Science Foundation of Chonqqing (No. 2004-47, CSTC2007BB5286).

\section{REFERENCES}

[1] Wang H , Dey SK. Roadmap to embryo implantation: clues from mouse models. Nat Rev Genet, 2006, 7: 185-199

[2] Krüssel JS, Bielfeld P, Polan ML, Simón C. Regulation of embryonic Implantation. European Journal of Obstetrics and Gynecology and Reproductive Biology, 2003, 110: 2-9

[3] Bedard K, E Szabo E, Michalak M, Opas M. Cellular functions of endoplasmic reticulum chaperones calreticulin, calnexin, and ERp57. Int Rev Cytol, 2005, 245: 91-121

[4] Mesaeli N, Nakamura K, Zvaritch E, Dickie P, Dziak E, Krause KH, Opas M, MacLennan DH, Michalak M. Calreticulin is essential for cardiac development. J Cell Biol.1999, 144: 857-868

[5] Meldolesi J, Pozzan T. The endoplasmic reticulum $\mathrm{Ca} 2+$ store: a view from the lumen. Trends Biochem Sci, 1998, 23: 10-14

[6] Corbett, EF, Michalak M. Calcium, a signaling molecule in the endoplasmic reticulum? Trends Biochem Sci, 2000, 307-311

[7] Coppolino M, Leung-Hagesteijn C, Dedhar S, Wilkins $\mathrm{J}$. Inducible interaction of integrin a2131 with calreticulin-dependence on the activation state of the integrin. J Biol Chem, 1995, 270: 23132-23138

[8] Papp S, Fadel MP, Kim H, McCulloch CA, Opas M. Calreticulin affects focal contact-dependent but not close contact-dependent cell-substratum adhesion. J Biol Chem, 1999, 274: 15085-15094 
[9] Otteken A, Moss B. Calreticulin interacts with newly synthesized human immunodeflciency virus type 1 envelope glycoprotein, suggesting a chaperone function similar to that of calnexin. J Biol Chem, 1996, 271: 97 103

[10] Michalak M, Corbett BF, Mesaeli N. Calreticulin: one protein, one gene, many functions. Biochem J, 1999 , 344: 281-292

[11] Burrows TD, King A, Loke YW. Trophoblast migration during human placental implantation. Hum Reprod, 1996, Update 2 : 307-321

[12] Burghardt RC, Johnson GA, Jarger LA, Ka H, Garlow JE, Spencer TE, Bazer FW. Integrins and Extracellular Matrix Proteins at the Maternal-Fetal Interface in Domestic Animals. Cell Tissues Organs, 2002, 172: 202-217

[13] Tan Y, Gu ML, Wang ZB. Collection of uterine endometrium of mouse during peri-implantation period. Chinese J of Lab Animal Sci, 2001, 9: 40-44

[14] Zhu LJ, Bagchi MK, Bagchi IC. Attenuation of calcitonin gene expression in pregnant rat uterus leads to a block in enbryonic implantation. Endocrinology, 1998, 139(1): 330-339

[15] Liu YX. Plasminogen activator/plasminogen activator inhibitors in ovarian physiology. Front Biosci, 2440, 9: 3356-3373

[16] Coppolino MG, Dedhar S. Ligand-specific, transient interaction between integrins and calreticulin during cell adhesion to extracellular matrix proteins is dependent upon phosphorylation/dephosphorylation events, Biochem J, 1999, 340: 41-50

[17] Reilly D, Larkin D, Devocelle M, Fitzgerald D J, Moran N. Calreticulin-independent regulation of the platelet integrin alphaIIbbeta3 by the KVGFFKR alphaIIb-cytoplasmic motif, Platelets, 2004, 15: 43-54

[18] Wang J, Armant DR. Integrin-mediated adhesion and signaling during blastocyst implantation. Cells Tissues Organs, 2002, 172: 190-201

[19] Lessey BA, Arnold JT. Paracrine signaling in the endometrium: integrins and the establishment of uterine receptivity. J Reprod Immuno, 1998, 39: 105-116
[20] Wang X, Matsumoto H, Zhao X, Das SK, Paria BC (2004) Embryonic signals direct the formation of tight junctional permeability barrier in the decidualizing stroma during embryo implantation. J Cell Sci, 1998, 117: 53-62

[21] Lessey BA, Damjanovich L, Coutifaris C, Castelbaum A, Albelda SM, Buck CA. Integrin adhesion molecules in the human endometrium. Correlation with the normal and abnormal menstrual cycle. J Clin Inves, 1992, 90: 188-195

[22] Lessey BA, Castelbaum AJ, Sawin SW, Buck CA, Schinnar R, Bilker W, Strom BL. Aberrant integrin expression in the endometrium of women with endometriosis. J Clin Endocrinol Metab, 1994, 79: 643649

[23] Leung-Hagesteijn CY, Milankov K, Michalak M, Wilkins J, Dedhar S. Cell attachment to extracellular matrix substrates is inhibited upon downregulation of expression of calreticulin, an intracellular integrin alpha-subunit-binding protein. J Cell Sci, 1994, 107: 589-600

[24] Fadel MP, Dziak E, Lo CM, Ferrier J, Mesaeli N, Michalak M, Opas M. Calreticulin affects focal contact-dependent but not close contact-dependent cellsubstratum adhesion. J Biol Chem, 1994, 274: 1508515094

[25] Fadel MP, Szewczenko-Pawlikowski M, Leclerc P, Dziak E, Symonds JM, Blaschuk O, Michalak M, Opas M. Calreticulin affects beta-catenin-associated pathways. J Biol Chem, 2001, 276: 27083-9

[26] Jin-Xiang Yuan, Li-Juan Xiao, Cui-Ling Lu, Xue-Sen Zhang, Tao Liu, Min Chen, Zhao-Yuan Hu, Fei Gao, Yi-Xun Liu.Increased expression of heat shock protein 105 in rat uterus of early pregnancy and its significance in embryo implantation. Reproductive Biology and Endocrinology; 2009, 7: 23

[27] Wagner RW. Gene inhibition using antisense oligodeoxynucleotide. Nature, 1994, 372(6504): 333 335 